\title{
SOBRE LA ANEXION DE GUARDAMAR A ORIHUELA
}

\author{
Rosa María Blasco
}

El rastreo por los archivos no siempre conduce al encuentro de lo que el investigador va buscando. Pero también es cierto que otras veces, de modo fortuito, se descubren documentos que vale la pena dar a conocer, pues el estudio y la recopilación de estas noticias dispersas permitirá matizar y aclarar muchos aspectos de nuestra historia.

En unas hojas sueltas conservadas en el Archivo Municipal de Orihuela aparece la copia notarial de un documento expedido por la cancillería de Pedro IV, que recoge la tirantez de relaciones existente entre los lugares de Orihuela y Guardamar. La anexión de Guardamar a Orihuela era un tema que venía suscitando pleitos y sentencias desde mucho tiempo atrás. Durante el reinado de Pedro IV se quiere zanjar la cuestión, y el documento que recoge las vicisitudes al respecto es una sentencia fallada en 1371 por D. Juan Jimeno de Salanova, caballero, licenciado en leyes, consejero y auditor de la curia regia. La sentencia se hace pública en Valencia el sábado, 6 de septiembre «alrededor de la hor de vísperas», en casa del noble Pedro Boil, donde se hospedaban el rey y la reina. 
Tal vez el mayor interés del documento reside en que viene a ser un «estado de la cuestión» que nos muestra el esfuerzo de las partes a lo largo de casi un siglo, por dirimir el tema. El perdedor reiteradamente vuelve a exponer sus peticiones, y esto genera una amplia documentación que encontramos aquí citada.

La referencia más antigua que habla de la pertenencia de Guardamar a Orihuela, se encuentra en un documento de Alfonso X el Sabio, de 1266; extremo que se encuentra ratificado en otro privilegio del mismo monarca sobre términos, de 1274. Por entonces Guardamar se llamaba Almodóvar. Sancho IV confirma la anexión en un privilegio de 1284 .

Durante la primera mitad del S.XIV Guardamar logra ser villa autónoma; con todo, también de estos años hay referencias documentales de los problemas sobre límites de términos entre Guardamar y Elche, tema que se resuelve mediante sentencia el 13 de junio de 1323.

En castigo por su apoyo a Castilla durante la guerra de los dos Pedros, fue anexionada de nuevo a Orihuela, por privilegio de Pedro IV fechado el 4 de septiembre de 1364.

El documento que transcribimos hace referencia también a una carta pública de 8 de marzo de 1368 , donde se relata cómo el justicia de Orihuela tomó posesión de Guardamar.

Tres años después sobreviene otro breve paréntesis autonómico, gracias a una concesión real otorgada el 17 de marzo de 1371. Pero sólo tres meses más tarde se fallará la sentencia que publicamos, y que el 18 de septiembre se corrige en el sentido de suprimir una condición que aparecía en la redacción primitiva publicada el día 6. Se trata de la cláusula que aludía a la obligación por parte de Orihuela de conservar y mantener el castillo, muros y fortalezas de Guardamar. La corrección supone que en adelante actuen en este punto como era costumbre antes de que Guardamar se convirtiera en aldea de Orihuela.

Otra cláusula previene que los hombres de Guardamar no se encuentren sobrecargados en la contribución, para evitar que despueblen el lugar. Finalmente, sobre el modo de ejercer la justicia en Guardamar, se fija como modelo y pauta la que lleva a cabo el justicia de Valencia en Murviedro. 


\section{CARACTERES EXTERNOS}

El documento aparece copiadọ en siete páginas de $320 / 220 \mathrm{~mm}$., sobre papel verjurado, con marca de agua en dos de sus hojas. La escritura es humanística. La tinta, parda, ha quedado desvaída en muchos tractos, por las manchas de humedad que afectan al papel. En general su estado de conservación es deficiente. Se trata de una copia notarial, signada, sin fecha, posiblemente de finales del S.XV. El latín alterna con el valenciano, reservándose el primero para los párrafos más formularios del documento.

\section{TRANSCRIPCION}

In Dei Nomine. Pateat universis quod nos Petrus, Dei graçia rex Aragonum, Valentiae, Maioricarum, Sardiniae et Corsicae, comesque Barchinone, Rossilionis et Ceritaniae. Attendentes diversas questiones seu controversias fuisse exortas inter universitate ville Oriolae ex parte una, et universitate loci de Guardamar ex altera, rationibus inferius declaratis, tandem recognitis privilegiis utrique parti concessis et procesibus super his habitis et in nostro consilio recensitis ac super eis tam in nostri presençia quam coram alquibus de nostro consilio ad hoc per nos deputatis habitis collationisbus in quibus inter fuerunt doctores et iurisperiti solennnes et partium advocati dictis quod privilegiis ac processibus et rationibus utrinque propositis plenarie et diligenter discussis die presenti partibus ad audiendum sententiam assignata sententiam super hiis ferimus in hunc modum. Nos Petrus, etc. Vista primerament una sentencia per en Joan Martínez D'Esllava, axi com a procurador la donchs de la vila de Oriola, XII dia septembris anno $\mathrm{M}^{\circ} \mathrm{CCC} \ll \mathrm{LX}^{\circ}$ tertio promulgada. Vist en apres un privilegi o concessio per nos a la vila de Oriola otorgat, per vigor del qual nos haviem declarat donat et novellament otorgat quel lloch de Guardamar en molts altres, en espeçial ibidem expressats, fos de terme e territori de la dita vila de Oriola, segons que per lo dit privilegi, quarta die septembris anno millesimo $\mathrm{CCC}^{\circ} \mathrm{LX}^{\circ}$ quarto atorgat clarament se demostra. Vist ulterius com per vigor del dit privilegi lo justiçia de la dita vila de Oriola, en nom de la universitat de aquella, fon mes en possessio del lloch de Guardamar, terme e territori e pertinençes de aquell per lo nostre governador de Oriola, segons que per carta publica 
daguen feta VIII die marcii anno millessimo $\mathrm{CCC}^{\circ} \mathrm{LX}$ octavo, appar pus llargament. Reconeguda encara una concessio per nos al nostre procurador de Oriola, XVII die marcii anno $\mathrm{M}^{\circ} \mathrm{CC}^{\circ} \mathrm{LXX}^{\circ}$ primo feta, per vigor de la qual lo dit governador priva e qita realment e de fet la vila e universitat de Oriola de la posessio del lloch de Guardamar, termes et pertinençies sues, et lo dit lloch de Guardamer reintegra et rediu en la sua primera e pristina possessio segons que per llectura del proçes daquen actitat clarament se demostra. Vist deinceps un privilegi del rey Nalfons de Castella, ab lo qual entre les altres coses atorga que lloch de Almodover, lo qual es ara appellat Guardamar, fos de la vila de Oriola, ab tots sos termens, fons e pastures, lo qual son donat sub era Millessima $\mathbf{C C C}^{\mathrm{a}}$

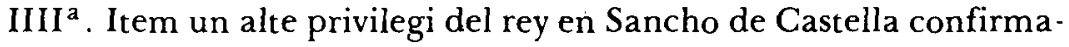
vit in effectu lo sobredit privilegi, sub era Millessima $\mathrm{CCC}^{\mathrm{a}} \mathrm{XXI}^{\mathrm{a}}$ atorgat. Item apres una executoria de les damunt dits privilegis, per vigor de la qual lo adelantat la donchs del regne de Murçia mes en possessio realment e de feyt a la vila de Oriola del lloch de Guardamar senyaladament, lo qual antigament era nomenat Almodover, segons que appar clarament per una carta publica, quarta die julii, sub era millesima $\mathrm{CCC}^{\mathrm{a}} \mathrm{XX}^{\mathrm{a}}$ daquen feta. Vist deinceps molts privilegis et confirmaçions de aquells, axi per nos com per un dit infant en Ferando, aqui pro tunc los dits llochs se pertanyen sots diversos calendaris atorgats. Vistes ulterius moltes et diverses coses per part del lloch de Guardamar proposades, produhides e allegades. Et signanter una sentençia per lo dit Infant sobre la partiçio e llimitaçio de termens entre la vila de Oriola e lloch de Guardamar sobredits XXIII die junii anno $\mathrm{M}^{\circ} \mathrm{CCC}^{\circ} \mathrm{LVII}^{\circ}$ donada e promulgada. Vista denique una altra sentençia entre lo lloch de Guarda. mar e lloc d'Elx per la universitat de Oriola jurats o regidors d'aquella per via arbitral e de compromes sobre la petiçio dels termens de aquells, XIII die junii anno $\mathrm{M}^{\circ} \mathrm{CCC}^{\circ} \mathrm{XX}^{\circ}$ tercio promulgada. Item res nomenys un privilegi del rey Nanfos de Castella les partiçions e fites de termens antigament fets XXVIII die octobris sub era $\mathrm{M}^{\mathrm{a}} \mathrm{CCC}^{\mathrm{a}} \mathrm{XI} \mathrm{I}^{\mathrm{a}}$ confirmam. Vista etiam una concessio per lo dit rey de Castella de les salines majors de Oriola, exceptan les salines menors de Guardamar a la dita vila de Oriola, feta quinta die Marcii sub era $\mathrm{M}^{\mathrm{a}} \mathrm{CCC}^{\mathrm{a}} \mathrm{XXI}^{\mathrm{a}}$ atorgada. Vista encara una altra confirmaçio del dit infant per lo lloch de Guardamar, sub calendario XVII die madii anno a nativitate domini Millesimo $C C C^{\circ} \mathrm{L}^{\circ}$ 
tertio obtenguda. Vistes insuper moltes e diverses rahons e impugnaçions per part de Guardamar contra la sentençia d'en Joan Martínez D'Eslava desuper nomenada, fetes e proposades. Vistes ulterius moltes e diverses rahons, excepçions e replicaçions per la una e la altra part vicisim donades, posades e allegades, segons que per lo proçes llargament daquen actitat appar, del qual davant la nosta circunspecçio real e de nostre gran consell, e presents los procuradors e sindichs de la dita vila de Oriola e lloch de Guardamar, es estada feta relaçio plena per l'amat conseller e oydor de la nostra cort Joan Ximénez de Salanova, cavaller y licençiat en leys. Attenents signanter que la deçisio e determinaçio del present plet e questio solament penja e esta en nostra mera voluntat e total disposiçio pre maxime com en disposiçio e franch poder de tot gran rey e prinçep sia e estiga de crear o novellament induhir çiutats, castellas, viles e altres llochs, e a termenar mollonar o llimitar aquells, e molt mes ja constituhides e constituhits renovellar mudar o alterar. Nec non etiam quod est maius fer e introduhir novellament provinçia o provinçies, e de una dividir e constituhir dues o moltes. Et en converso, dues provinçies o moltes tornar e reduhirles a una. Et longe fortius in pluribus civitatibus villis seu locis maxime aliquibus parum insignibus existentibus segons que en lo present cas manifestament es trobat. Considerada ulterius la declaraçio e encara lliberal concessio del dit lloch de Guardamar ab totes ses perinençies per la nostra magnificençia a la dita vila de Oriola, diu est fetes e atorgades e les causes e rahons en aquelles contengudes e expresades, que reduhit lo dit lloch de Guardamar sots terme e jurisdicçio de la vila de Oriola es expedient e profitos al regne de Valençia e a la cosa publica, e molt maior tuiçio e defensio del dit lloch de Guardamar, e per conseguent maior servir nostre e dels nostres regnes. Per tal, moguts per les dites rahons e per moltes altres que poden e deven moure e induhir voluntat e coratge de tot gran rey, princep e señor, presents los procuradors e sindichs de la vila de Oriola e del lloch de Guardamar sobre dits. Et supplicants e instants diligentement, cascu per si e part sua, sentençia e declaraçio sobre lo dit pleyt, e questio per part sua esser donada estants com a rey, princep e señor e en lloch apte e convinent a jutgar, e havents los sants evangelis de Deu davant nos, e lo nom seu humilment appellat, pronunçiam, declaram e volem la donaçio e concessio del dit lloch de Guardamar, termens e pertinençes de 
aquell a la dita vila de Oriola, pr nos iam diu est feta esser ferma e valida, et deinceps in omni tempore permansura iuxta sa continençia e tenor. $\mathrm{E}$ per conseguent la dita vila de Oriola realment e de fet es mesa, tornada e reduhida en la posessio del lloch de Guardamar termens e pertinençies sues, iuxta la forma e tenor de la dita nostra concessio de la qual era estada privada. Etenim empero e expressament ordenam e volem a sots tal manera e condiçio lo dit nostre privilegi e donaçio confirmam e validam, que la vila de Oriola, universitat e singulars de aquella sien tenguts de tenir, conservar e mantenir lo castell, murs, valls e fortaleses del dit lloch de Guardamar, segons que a conservaçio e tuiçio del castell e forçes sobredites fer convendra. Volem e ordenam encara que en tems de guerra o de altra necesitat evident la universitat de la vila de Oriola sia tenguda fornir e bastir lo dit castelle vila baixa del dit lloch de Guardamar, axi de gents com de viandes e altres coses que a defenssio de les dites fortaleses seran vistes neçessaries. Volem e manam axi mateix quels habitadors qui a present son en lo dit lloch de Guardamar e los qui d'aqui avant hy seran sien axi be e favorablement pertractats com los vehins e habitadors de la vila de Oriola. Etenim empero e volem que per la present sentençia e coses en aquella contengudes no sia fet ni engenrat algun prejuhi, lesio o derogaçio alguna a nostres drets e emuluments, rendes o altres qualsevol regalies a nos per quelque raho o manera pertanyents. Lata fuit hec sententia per dictum dominim rege et per Joannem Eximini de Salanova, militem in legibus licenciatum, consiliarum et auditorem curie dicti domini regis qui mandato ipsius domini regis ipsam sententiam ordinaverat. Lecta seu publicata die sabbati, sexta die septembris circa horam vesperorum, anno a nativitate domini $\mathrm{M}^{\circ} \mathrm{CCC}^{\circ} \mathrm{LXX}^{\circ}$ primo, in civitate Valentiae, videlicet in ospicio nobilis ospitabantur, presentibus proparte fiscis dictidomini regis Laurencio Terrats regente thesaurariam ipsius domini regis pro Petro Vallo dictam thesauraria pro domino rege regente, et pro parte dicte ville Oriole Berengario de Vinbodi, sindico et procuratore universitatis ipsius ville Oriole ex parte una, de quo sindicatu fidem feçit per quoddam publicum instrumentum factum Oriole clausumque et subsignatum per Franciscum de Podio notarium publicum, vicessima secunda die febroarii anno a nativitate domini $\mathrm{M}^{\circ} \mathrm{CCC}^{\circ}$ septuagesmo. Et pro parte dicti loci de Guardamar Bartholomeo Yvanyes, sindico et procuratore universitatis dicti loci 
de Guardamar ex altera, de quo sindicatu fidem fecit per quoddam aliud publicum instrumentum factum in loco de Guardamar clausumque et subsignatum per Joannem de Fontes notarium publicum, quarta die madii anno a nativitate domini $\mathrm{M}^{\circ} \mathrm{CCC}^{\circ}$ septuagesimo primo, Nec non Reymundo Castellano et Enmanuelle d'Entença, militibus, et Petro Çalam in legibus licenciato ac Francisco Castilionis scriptore memorati dominum regis ad hec pro testibus specialiter evocatis. De quibus predictus sindicus et procurator dicte universitatis ville Oriole requisivit et utique dictus dominus rex mandavi ei et dictae villae Oriolae fieri publicum instrumentum in testimonium rei gestae presentibus dicto sindico et procuratore loci predicti de Guardamar et testibus supradictis. Sicut postea cum inter dictas partes Oriole et de Guardamar moveretur questio seu dabatur de alius super aliquibus verbis positis in dicata sententia ex quibus utraque pars se oneratam plurimum reputabat pariter et gravatam dictus dominus rex auditis per eum seu per deputatos ab eo iam dictis partibus et per eudem dominum regem informatione ac delibaratione plenaria habita super eis constitutus personaliter in dicto ospicio dicti nobilis Petro Boil et presentibus pro parte dicti domini regis dicto Laurentio Terrats et pro parte dicte ville Oriole dicto Berengario de Vimbodi, in absentia tamen dicti Bartholomei Yvanies sindici et procuratoris loci predicti de Guardamar que mandatum habuerat quod instaret continue et esset presens pro audienda declaratione subscripta ac pro testibus nobili Ramundo Alamanni de Cervilione, militi, gerente vices gubernatoris regni Valenciae et Petro de Marginibus, scriptore portionis ac consiliaris dicti domini regis, die jovis, decima octava die septembris, anno predicto a nativitate domini $\mathrm{M}^{\circ} \mathrm{CCC}^{\circ} \mathrm{LXX}{ }^{\circ}$ primo, fecit et promulgavit inter dictas partes declarationem squentem. Corregim la sentençia damunt dita e milloram aquella declaram la dita universitat de Oriola e singulars de aquella no esser tenguts obrar conservar ne tenir en condret mantenir o en alguna manera fornir lo castell, murs, valls e fortalees del dit lloch de Guardamar, e ans aquestes coses se haien a fer segons que era acostumat abans que nos faessem aldea lo dit lloch de Guardamar, exceptat que dels terratinents se faça segons que per no es estat declarat en les corts. Ne ay tanpoch los dits homens de Guardamar sien tenguts obrar, pagar e contribuhir en la obra o reparaçio del caste!l ne dels murs e valls de Oriola ans aço se haia a fer segons que era acostumat que 
ans que faeseem aldea lo dit lloch de Guardamar. Empero los dits homens de Guardamar sien tenguts en per tots temps pagar e contribuhir al los homens de Oriola en tots tans e altes qualsevol carrechs reals e vehinals axi com aldea de Oriola. Aço retengut e declarat que en alguns deutes o carrechs deguts o fets tro al present dia de huy per la universitat de Oriola los homens de Guardamar no sien tenguts pagar o contribuhir alguna cosa. Et declarar encara que la universitat de Oriola se haje devers los homens de Guardamar per tal manera en la contribuçio que ab ella haurian a fer que non sien sobres carregats ne sia donada materia a aquells de despoblar lo dit lloc com si ho fahien seria cosa que nos no soferriem. E quant al fet de la juredicçio e justiçiat del dit lloch de Guardamar volem e declaram que sia exerçida es faça de tot en tot segons qu'es exerçeix en la vila de Morvedre per lo justiçia de Valençia. E no res menys que en cas de guerra o de evident necessitat la dita universitat de Oriola sia tengud de aiudar e defendre lo dit lloch de Guardamar segons que vila es tengude de aiudar e defendre la aldea a coneguda del governador de Oriola e totes les altres coses contengudes en la dita sentençia exçeptades aquestes coses que ara havem corregudes en la dita sentençia per la present declaraçio romanguen en sa força e valor. Que declaraçio lata fuit perdictum dominum regem die proxime dicta presentibus partibus et testibus supra proxime nominatis quamque declarationem dictus dominus rex hic inseri et continuari mandavit et voluit in omnibus robur sententie obtinere. Et de predictis omnibus et singulis memoratus Berengarius de Vimbodi nomine et pro parte dictae ville Oriole requisivit et dictus dominus rex mandavit fieri sibi et dicte ville Oriole publicum instrumentum in testimonium veritatis. Quare ad mandatum dicti domini regis et dicti sindici ac procuratoris ville predictae Oriolae instanciam fuit factum de predictis sentençia ac declaratione et aliis premissis presens publicum instrumentum per me Bernardum de Bonastre eiusdem domini regis secretarium et notarium infrascriptum et parti ipsius villae Oriolae traditum. Quod fuit actum loco, diebus et anno prefixis. Signum + Petri Dei gratia regis Aragonum, etc. que predictam sententiam tuhimus et inde hanc cartam fieri et ei sigillum nostrum apponi iussimus impendenti. Signum + mei Bernardi de Bonastre dicti nomine regis secretarii eiusque autoritate notarrii publici per totam terram et dominationem suam, qui premissis inter fui et hec scribi feci. 